\title{
A PUBLICIDADE NA ADVOCACIA EM FACE DO NOVO CÓDIGO DE ÉTICA E DISCIPLINA DA OAB ${ }^{1}$
}

ADVERTISING IN LAW FACING THE OAB'S NEW CODE OF ETHICS AND DISCIPLINE

Kaique Souza PEDAES ${ }^{2}$

ISSUE DOI: $10.21207 / 2675-0104.2018 .730$

\begin{abstract}
RESUMO
O principal objetivo deste trabalho é desvendar a natureza da publicidade na advocacia e analisar formas permitidas e vedadas de se realizar publicidade, em consonância com o novo Código de Ética e Disciplina da OAB, em vigor desde setembro de 2016, e conforme a jurisprudência do Tribunal de Ética e Disciplina da OAB/SP. Para tanto, utilizou-se das pesquisas bibliográfica e documental, de modo que foi possível apresentar, dentre diversos temas, a distinção entre publicidade e propaganda, além de analisar os motivos éticos da proibição do uso de certos veículos de difusão de informações, como cinema, rádio e televisão, em oposição ao que se vê em seriados norte-americanos, como Breaking Bad e Better Call Saul.
\end{abstract}

Palavras-chave: Publicidade. Propaganda. Ética. Advogado. OAB.

ABSTRACT

The main objective of this work is to unveil the nature of publicity in advocacy and to analyze permitted and prohibited forms of publicity, in line with the new OAB's Code of Ethics and discipline, in force since September 2016, and according to the jurisprudence of the OAB's Court of Ethics and discipline. To do so, it was used bibliographical and documentary research, so that it was possible to present, among several themes, the distinction between publicity and advertising, as well as to analyze the ethical reasons for the prohibition of the use of certain information dissemination vehicles, such as cinema, radio and television, as opposed to what is seen in American TV shows such as Breaking Bad and Better Call Saul.

\footnotetext{
${ }^{1} \mathrm{O}$ presente artigo sintetiza a monografia de conclusão da pesquisa, realizada para o Programa Interno de Bolsas de Iniciação Científica (PIBIC 2017-2018) da Faculdade de Direito de Franca (FDF), Franca/SP.

${ }^{2}$ Discente da Faculdade de Direito de Franca (FDF), Franca/SP. Bolsista do Programa Interno de Bolsas de Iniciação Científica (PIBIC 2017-2018).
} 
Keywords: Publicity. Advertising. Ethics. Lawyer. OAB.

\section{INTRODUÇÃO}

Dentre os diversos ofícios executados na sociedade, é de notório reconhecimento social a função do advogado. Trata-se de uma figura indispensável à administração da Justiça, como prevê o artigo 133 da Constituição Federal. Nesse sentido, esta tarefa deve ser realizada sob a observância de preceitos éticos e morais.

Estes preceitos são estabelecidos pelo novo Código de Ética e Disciplina da OAB, que entrou em vigor em setembro de 2016, substituindo o código que vigorava desde 1995. O CED cuida de diversos assuntos, e dentre eles está a publicidade realizada pelos advogados, cujo tema é objeto desta pesquisa, motivada pela escassez doutrinária sobre assunto muito relevante.

De início, este trabalho tem como meta distinguir publicidade e propaganda, termos muitas vezes usados como sinônimos, mas que possuem significados diferentes.

Em seguida, pretende-se analisar a natureza da publicidade na advocacia e as regras que norteiam este relevante tema, esclarecendo, desta forma, porque observa-se em séries norte-americanas, por exemplo, advogados veiculando publicidade pela televisão e em locais públicos, enquanto no Brasil isso não é visto.

Por fim, esta investigação propõe-se a apresentar formas vedadas de publicidade, e como é possível realizar a publicidade corretamente, respeitando os preceitos éticos e valorizando a advocacia, em vista do necessário combate à mercantilização de uma das mais nobres profissões existentes.

A pesquisa bibliográfica, representada pelo levantamento de referências teóricas já analisadas e publicadas por meios escritos e eletrônicos, como livros e páginas de web sites, tem inegável contribuição para o desenvolvimento deste trabalho. Todavia, esta investigação científica não poderia atingir seus objetivos valendo-se somente deste procedimento.

Utiliza-se também da pesquisa documental e jurisprudencial, por meio da qual são analisados pareceres do Tribunal de Ética e Disciplina da OAB de São Paulo, que, por oferecer interpretação prática das normas sobre publicidade e proferir ensinamentos a respeito da natureza da 
publicidade na advocacia, auxilia substancialmente a elaboração do trabalho.

\section{PUBLICIDADE E PROPAGANDA}

Numa sociedade capitalista, a propaganda exerce papel fundamental na divulgação de produtos e serviços. Há até mesmo quem acredite que ela representa a alma do negócio. Assim, a tendência é que os investimentos publicitários sejam maiores a cada ano que passa.

Segundo levantamento realizado pela Kantar IBOPE Media em 2017, no Brasil, mais de 84 mil marcas foram expostas na mídia - volume $1,4 \%$ superior ao registrado em 2016 - e o investimento publicitário movimentou R\$ 134 bilhões $^{3}$.

Esses números mostram a importância que as empresas dão para a publicidade. Afinal, não se pode negar o impacto causado por um anúncio bem estruturado.

Mas, para atingir seus objetivos, "a propaganda comercial deve ser atrevida e ruidosa", conforme os ensinamentos de Ludwig von Mises, pois é dessa forma que ela será capaz de fornecer aos consumidores "informações sobre a efetiva situação do mercado", "atrair a atenção das pessoas mais lentas" e "despertar desejos latentes".

Em síntese, no ambiente empresarial, a propaganda deve tentar influenciar o público consumidor. Em contrapartida, esta ideia não pode prosperar no campo da advocacia pátria.

O advogado, como figura indispensável à administração da Justiça, e em razão da elevada função pública que exerce, não pode adotar em seus atos quaisquer procedimentos de mercantilização, por serem estes incompatíveis com sua profissão. O causídico "não vende produto, mas presta serviço especializado" ", adverte o Tribunal de Ética e Disciplina da $\mathrm{OAB} / \mathrm{SP}$.

\footnotetext{
${ }^{3}$ KANTAR IBOPE MEDIA. Mais de 84 mil marcas foram expostas na mídia em 2017. Disponível em: <https://www.kantaribopemedia.com/mais-de-84-mil-marcas-foramexpostas-na-midia-em-2017>. Acesso em: 15 fev. 2018.

4 VON MISES, Ludwig. Ação humana. Tradução por Donald Stewart Jr. São Paulo: Instituto Ludwig von Mises Brasil, 2010, p. 381.

${ }^{5}$ SÃO PAULO. Primeira Turma de Ética Profissional do Tribunal de Ética e Disciplina da OAB. Proc. 1.684/98. Relator Dr. João Teixeira Grande. São Paulo, 21 de maio de 1998. Disponível

em:
} 
Dessa forma, o Código de Ética e Disciplina proíbe que o advogado realize propaganda, permitindo-se, somente, a promoção da publicidade profissional.

Apesar de muitas vezes serem tratados como sinônimos, os termos publicidade e propaganda, essencialmente, apresentam significados diferentes, com aquele possuindo sentido mais restrito que este, como ensina o TED da OAB/SP, em julgado de agosto de 2017:

[...] A propaganda cria estímulo, incentiva demanda e faz uso da ampla divulgação por meio de todos os veículos. Usa a imagem, o som, os recursos gráficos, a informática, luminosos, placas, faixas, panfletos, encartes, mala direta, televisão, cinema, rádio, altofalantes, carros de som. A publicidade é mais discreta porque seu objetivo é o de tornar pública uma informação dirigida a um público mais reservado $[\ldots]^{6}$.

Nesse sentido, fica claro que, à luz da legislação vigente e do entendimento jurisprudencial, é lícito ao advogado fazer publicidade, mas não propaganda.

\section{$3 \quad$ NATUREZA DA PUBLICIDADE NA ADVOCACIA}

Estabelecidas as diferenças entre publicidade e propaganda, é possível seguir adiante e abordar o caráter da publicidade para os advogados.

O primeiro artigo do Capítulo VIII do Código de Ética e Disciplina traz as regras gerais que norteiam como deve ser realizada a publicidade na advocacia, tendo em vista que os demais dispositivos não esgotam o assunto - este sequer é o objetivo - e somente especificam algumas formas permitidas e vedadas de publicidade.

Inicialmente, o art. 39 define que a publicidade tem caráter meramente informativo e deve primar pela discrição, moderação e sobriedade, não podendo configurar captação de clientela ou

<https://www2.oabsp.org.br/asp/tribunal_etica/pop_ementas.asp?tipoEmenta=1\&ano=199 8\&id_sessao=4\&sequencial=8>. Acesso em: $15 \mathrm{fev} .2018$.

${ }^{6}$ SÃO PAULO. Primeira Turma de Ética Profissional do Tribunal de Ética e Disciplina da OAB. Proc. E-4.857/2017. Relator Dr. Luiz Antonio Gambelli. São Paulo, 17 de agosto de 2017.

Disponível

em: <https://www2.oabsp.org.br/asp/tribunal_etica/pop_ementas.asp?tipoEmenta=1\&ano=201 7\&id_sessao=7\&sequencial=30>. Acesso em: 15 fev. 2018. 
mercantilização da profissão, afinal, "a advocacia não é um balcão de comércio", como prega o Tribunal de Ética paulista ${ }^{7}$.

Desse modo, entende-se que toda forma de publicidade que o advogado desejar, poderá ser realizada, mesmo que não prevista pelo código ou pelo Provimento $\mathrm{n}^{\circ}$ 94/2000 (documento elaborado pelo Conselho Federal da OAB e que também trata da publicidade). Afinal, "o fato de uma situação nova não ter sido prevista pelo legislador não a coloca fora do Direito", como ressalta Gladston Mamede ${ }^{8}$. Ao causídico basta apenas que a forma publicitária não seja expressamente vedada e que encontre amparo nas diretrizes estabelecidas pelo art. 39.

Tais diretrizes já estavam previstas no Código de Ética e Disciplina de 1995, que, assim como o regramento atual, seguia o modelo francês de publicidade, em oposição ao modelo americano.

Marcus Vinicius Furtado Côelho ensina que a publicidade dos advogados nos Estados Unidos assemelha-se a atividade empresarial, "ao contrário da tradição francesa, que inspirou e continua a orientar esse aspecto da cultura jurídica de nosso país enquanto atividade intelectual"". Enquanto isso, a proteção quanto à publicidade não visa apenas ao cliente, como explica Robison Baroni:

\begin{abstract}
Os princípios de moderação e discrição não se limitam apenas à proteção do cliente ou do público em geral, mas também dos próprios advogados inscritos na Ordem, contra a conduta antiética de colegas no tocante à captação de clientela, através de artifícios de publicidade que desprestigiam a classe e, via de consequência, as instituições de direito ${ }^{10}$.
\end{abstract}

Diante o exposto, fica claro que toda e qualquer forma de publicidade deve seguir as regras deontológicas fundamentais, previstas

${ }^{7}$ SÃO PAULO. Primeira Turma de Ética Profissional do Tribunal de Ética e Disciplina da OAB. Proc. E-2.748/03. Relator Dr. Osmar de Paula Conceição Júnior. São Paulo, 11 de dezembro de 2003. Disponível em: $<$ https://www2.oabsp.org.br/asp/tribunal_etica/pop_ementas.asp?tipoEmenta=1\&ano=200 3\&id_sessao=11\&sequencial=1 >. Acesso em: 15 fev. 2018.

${ }^{8}$ MAMEDE, Gladston. A Advocacia e a Ordem dos Advogados do Brasil. 1. ed. Porto Alegre: Síntese, 1999. p. 341.

9 COÊLHO, Marcus Vinícius Furtado. Comentários ao novo código de ética dos advogados. 2. ed. São Paulo: Saraiva, 2017. p. 61.

${ }^{10}$ BARONI, Robison. Cartilha de Ética Profissional do Advogado. 4. ed. São Paulo: LTR, 2001.p. 151. 
nos artigos $5^{\circ}$ e $7^{\circ}$ do $\mathrm{CED}$, que tratam, respectivamente, da mercantilização da profissão e da captação de clientela, pois, segundo o TED de São Paulo o reconhecimento da atividade advocatícia não deve decorrer da publicidade, mas "pela competência e conhecimento jurídico do advogado/sociedade de advogados, sua capacidade de inspirar confiança e assegurar segurança aos clientes na aplicação do direito" ${ }^{11}$.

Como resultado de todo o apresentado até aqui, a propaganda na advocacia é vedada e permite-se somente a publicidade de caráter informativo, ou seja, aquela em que o advogado torna públicas informações objetivas a seu respeito, demonstrando tão somente a sua disponibilidade para atuar na defesa de quem necessitar de seus serviços. Não é o advogado quem deve procurar o cliente, mas, sim, o contrário.

\section{$4 \quad$ MEIOS UTILIZADOS PARA PUBLICIDADE}

Esta investigação científica não tem o propósito de esgotar o assunto, ao tratar de algumas formas de se realizar publicidade que estão em consonância - ou não - com a nova legislação (assim como o novo código não tem este objetivo), mas apresentar aos estudantes e operadores do Direito como é possível realizar publicidade respeitando as regras deontológicas, num estágio em que a ética é um dos únicos caminhos para a salvação da sociedade.

O objetivo almejado por este trabalho tem fundamento em decisão proferida pelo TED:

[...] A não-leitura do EAOAB e do CED dá ao jovem e a muitos antigos advogados a ideia de que, diante da competição, a mercantilização da profissão é a saída para o sucesso, fazendo com que se lancem à criação de espaços luxuosos em revistas, jornais, eventos e Internet para os seus ricos anúncios. Cavaletes nas calçadas, distribuição de panfletos e remessa de mala direta são tantos outros artifícios que visam ao lucro, em detrimento da

${ }^{11}$ SÃO PAULO. Primeira Turma de Ética Profissional do Tribunal de Ética e Disciplina da OAB. Proc. E-4.459/2014. Relator Dra. Renata Mangueira de Souza. São Paulo, 16 de abril de 2015.2 Disponível em: $<$ https://www2.oabsp.org.br/asp/tribunal_etica/pop_ementas.asp?tipoEmenta=1\&ano=201 $5 \&$ id_sessao $=3 \&$ sequencial $=1>$. Acesso em: 15 fev. 2018. 
capacidade, talento, honradez e nobreza no exercício profissional $[\ldots]^{12}$.

No tocante aos meios vedados de publicidade, que serão abordados a seguir, elas se dão em razão de proibição expressa pela lei ou pelo Tribunal de Ética e Disciplina da OAB/SP, por eventualmente configurarem captação de clientela ou mercantilização da profissão, ou por não respeitarem os requisitos da discrição e sobriedade, bem como o do caráter meramente informativo da publicidade.

De início, a veiculação de anúncios através da televisão representa um ótimo meio de divulgação de produtos e serviços. Afinal, a televisão está na casa de quase todos os brasileiros. Segundo pesquisa realizada pelo Instituto Brasileiro de Geografia e Estatística (IBGE), no último trimestre de 2016, apenas 2,8\% dos domicílios particulares do País não possuem o aparelho ${ }^{13}$.

Contudo, o advogado não pode veicular publicidade por meio da televisão (tampouco pelo rádio ou cinema), prática permitida em países como os Estados Unidos e representada nos seriados Breaking Bad (20082013) e Better Call Saul (2015-), da AMC. O motivo da vedação, segundo Baroni, é o estabelecimento de concorrência desleal, "pois os mais abastados teriam melhores oportunidades na produção de seus anúncios"14.

Isso não significa que no Brasil o profissional tem que se manter totalmente distante de programas ou entrevistas. Contudo, se eventualmente participar de programa de televisão ou de rádio, de entrevista na imprensa, de reportagem televisionada ou veiculada por qualquer outro meio, para manifestação profissional, ele deve visar a objetivos exclusivamente ilustrativos, educacionais e instrutivos, e não poderá fornecer seus dados de contato, como endereço e telefone, com exceção ao e-mail.

${ }^{12}$ SÃO PAULO. Primeira Turma de Ética Profissional do Tribunal de Ética e Disciplina da OAB. Proc. E-2.340/01. Relator Dr. João Teixeira Grande. São Paulo, 17 de maio de 2001. Disponível em: <https://www2.oabsp.org.br/asp/tribunal_etica/pop_ementas.asp?tipoEmenta=1\&ano=200 1\&id_sessao=4\&sequencial=5>. Acesso em: 15 abr. 2018.

${ }^{13}$ GANDRA, Alana. Pesquisa diz que, de 69 milhões de casas, só 2,8\% não têm TV no Brasil. Rio de Janeiro, 21 de fevereiro de 2018. Disponível em: $<$ http://agenciabrasil.ebc.com.br/economia/noticia/2018-02/uso-de-celular-e-acessointernet-sao-tendencias-crescentes-no-brasil>. Acesso em: 12 jul. 2018.

14 BARONI, Robison. Cartilha de Ética Profissional do Advogado. 4. ed. São Paulo: LTR, 2001. p. 156. 
Supramencionada regra que diz respeito ao fornecimento de dados de contato aplica-se igualmente às colunas e artigos literários, culturais, acadêmicos ou jurídicos publicados pelo advogado na imprensa. Ademais, em suas colunas ou textos, o profissional deve se atentar para não induzir o leitor a litigar e nem promover captação de clientela.

Desta forma, fica claro que, em suas aparições públicas, bem como nas colunas que mantiver nos meios de comunicação social e nos textos que por meio deles divulgar, o advogado deve ter como real finalidade a promoção do acesso da população à informação.

O propósito de esclarecimento de assunto jurídico de interesse geral é atitude admirável, pois instrui a comunidade acerca de seus direitos, dignifica a classe e efetiva o dever do advogado de "pugnar pela solução dos problemas da cidadania e pela efetivação dos direitos individuais, coletivos e difusos" (art. $2^{\circ}$, parágrafo único, IX).

Inovação trazida pelo novo código em relação ao diploma de 1995 é a possibilidade de veiculação da publicidade pela internet, prática que já era permitida pela jurisprudência e pelo Provimento no 94/2000. Neste meio de comunicação, a publicidade se apresenta de diversas maneiras. Exemplos são o uso das mídias sociais (Facebook, Instagram, Twitter, YouTube, LinkedIn etc), a publicação de artigos em blogs jurídicos, e a criação de site próprio.

Mas alerta o Código de Ética, em seu art. 46, que a publicidade veiculada pela internet ou por outros meios eletrônicos deverá observar as mesmas diretrizes que se aplicam a todas as demais formas de publicidade, ou seja, ela deverá ter caráter meramente informativo, primar pela discrição, moderação e sobriedade, e não poderá configurar captação de clientela ou mercantilização da profissão.

Nas mídias sociais, o advogado pode atuar como uma poderosa ferramenta no combate às chamadas fake news. Análise realizada pela Folha de S. Paulo mostrou que páginas que compartilham notícias falsas nas redes sociais engajaram cinco vezes mais do que as de jornalismo em janeiro de $2018^{15}$. Neste ambiente, a atuação de profissionais com conhecimento jurídico se mostra como um instrumento potencialmente importante na disseminação de informações fidedignas.

\footnotetext{
${ }^{15}$ PORTINARI, Natália; HERNANDES, Raphael. Fake news ganha espaço no Facebook e jornalismo profissional perde. São Paulo, fevereiro de 2018. Disponível em: <https://www1.folha.uol.com.br/poder/2018/02/fake-news-ganha-espaco-no-facebook-ejornalismo-profissional-perde.shtml>. Acesso em: 24 jul. 2018.
} 
Quanto ao uso de conteúdo patrocinado, "que consiste na contratação do Facebook para exibir publicidade da sociedade de advogados aos usuários", decidiu o TED que tal prática não fere a ética ${ }^{16}$.

Assim como televisão, rádio e cinema, também não podem ser utilizados para veiculação de publicidade outdoors e painéis luminosos - a menos que estes estejam localizados na fachada do escritório, respeitando a discrição e com finalidade exclusiva de identificação do local de trabalho do profissional.

Inscrições em muros, paredes, veículos, elevadores ou em qualquer espaço público também não são compatíveis com as diretrizes gerais da publicidade, conforme art. 40, III. O inciso IV do mesmo dispositivo veda a divulgação de serviços de advocacia juntamente com a de outras atividades ou a indicação de vínculos entre uns e outras, a fim de preservar o sigilo e a inviolabilidade do escritório de advocacia.

Portanto, não pode haver divulgação conjunta da advocacia com atividades como imobiliária, contabilidade, auditoria etc., e caso estes empreendimentos funcionem no mesmo prédio, o acesso ao ambiente de trabalho do causídico deverá ser independente e a sala de espera não poderá ser compartilhada ${ }^{17}$.

Além das já citadas, também são antiéticas as condutas do causídico que: responde com habitualidade a consulta sobre matéria jurídica nos meios de comunicação social e, nestes, debate causa sob patrocínio de colega, e não evita debate de caráter sensacionalista; aborda tema de modo a comprometer a dignidade da profissão e da instituição que o congrega; divulga ou deixa que sejam divulgadas listas de clientes e demandas; e insinua-se para reportagens e declarações públicas.

O novo CED suprimiu o $\$ 1^{\circ}$ do art. 31 do Código de 1995, que proibia referências a valores dos serviços, tabelas, gratuidade ou forma de pagamento, termos ou expressões que possam iludir ou confundir o público, informações de serviços jurídicos suscetíveis de implicar, direta

${ }^{16}$ SÃO PAULO. Primeira Turma de Ética Profissional do Tribunal de Ética e Disciplina da OAB. Proc. E-4.176/2012. Relator Dr. Flávio Pereira Lima. São Paulo, 18 de outubro de 2012.

Disponível em: <https://www2.oabsp.org.br/asp/tribunal_etica/pop_ementas.asp?tipoEmenta=1\&ano=201 2\&id_sessao $=8 \&$ sequencial $=9>$. Acesso em: 24 jul. 2018.

${ }^{17}$ SÃO PAULO. Primeira Turma de Ética Profissional do Tribunal de Ética e Disciplina da OAB. Proc. E-4.051/2011. Relator Dra. Célia Maria Nicolau Rodrigues. São Paulo, 20 de outubro de 2011. Disponível em: <https://www2.oabsp.org.br/asp/tribunal_etica/pop_ementas.asp?tipoEmenta=1\&ano=201 1\&id_sessao=9\&sequencial=2>. Acesso em: 17 jul. 2018. 
ou indiretamente, captação de causa ou clientes, bem como menção ao tamanho, qualidade e estrutura da sede profissional.

Mesmo ausentes no novo Código, estas práticas não se tornaram permitidas, porque ainda estão proibidas pelo Provimento $n^{\circ}$ 94/2000. Quanto aos valores dos serviços, deve-se atentar que a vedação fica por conta da divulgação da gratuidade de consultas; ou seja, o advogado não é obrigado a cobrar pelas consultas, ele apenas não pode tornar pública esta informação ${ }^{18}$.

Admitido pelo novo CED como veículo de publicidade está a telefonia, por meio da qual o advogado pode enviar mensagens a destinatários certos, desde que estas não impliquem o oferecimento de serviços ou representem forma de captação de clientela.

Embora vedado o envio de mensagens com o fito de oferecimento de serviços para o público em geral, o Tribunal de Ética e Disciplina da $\mathrm{OAB} / \mathrm{SP}$ considera lícito o encaminhamento de correspondência a colegas advogados, oferecendo serviços processuais para os causídicos que se encontram distantes do local em que certo ato precisa ser praticado, como protocolo de petição, por exemplo ${ }^{19}$.

Além de vedado o oferecimento de serviços para o público em geral, também é defesa a utilização de mala direta com o intuito de captação de clientela. Por outro lado, é admissível a divulgação de boletins, por meio físico ou eletrônico, sobre matéria cultural de interesse dos advogados, desde que sua circulação fique adstrita a clientes e a interessados do meio jurídico.

A publicidade estampada nos uniformes de times esportivos, em especial nas camisas de futebol, é uma das formas de publicidade que mais chama a atenção e mais dá retorno positivo no Brasil, tendo-se em conta que essa estratégia de marketing aposta no consumo e na paixão dos torcedores para obter resultados ${ }^{20}$.

18 MAMEDE, Gladston. A Advocacia e a Ordem dos Advogados do Brasil. 1. ed. Porto Alegre: Síntese, 1999, p. 336.

${ }^{19}$ SÃO PAULO. Primeira Turma de Ética Profissional do Tribunal de Ética e Disciplina da OAB. Proc. E-3.186/05. Relator Dr. Guilherme Florindo Figueiredo. São Paulo, 16 de junho de 2005. Disponível em: <http://www.oabsp.org.br/tribunal-de-etica-edisciplina/melhores-pareceres/E318605>. Acesso em: 24 jul. 2018.

${ }^{20}$ SÃO PAULO. Primeira Turma de Ética Profissional do Tribunal de Ética e Disciplina da OAB. Proc. E-4.621/2016. Relator Dr. Eduardo Perez Salusse. São Paulo, 26 de abril de 2016. 6\&id_sessao=3\&sequencial=5>. Acesso em: 6 abr. 2018. 
Um caso de sucesso no patrocínio de um time esportivo é o da Crefisa, que investe na Sociedade Esportiva Palmeiras desde janeiro de 2015. Desde sua entrada no futebol brasileiro, a Crefisa viu seu patrimônio líquido dobrar, o que representa um crescimento maior do que o de qualquer outra instituição financeira do Brasil. Em dezembro de 2017, o patrimônio líquido da empresa era de $\mathrm{R} \$ 4,4$ bilhões, enquanto no último mês de 2014, antes do início do patrocínio, era de R\$ 2,2 bilhões ${ }^{21}$. Assim, apesar de a Crefisa investir também em outros meios, fica claro que o patrocínio de times esportivos apresenta-se como uma interessante forma de publicidade. Mas, não para os advogados.

A divulgação mediante estampa de logomarca em camisa de equipe transparece imodicidade, sendo "equivalente a anúncio público em local de evento esportivo, muitas vezes reproduzido em televisão, com o fim precípuo de captação de clientela" ${ }^{22}$, como assevera o Tribunal de Ética e Disciplina da OAB/SP.

Assim, comete infração ética o advogado que insere seu nome ou de seu escritório em uniformes de agremiações esportivas mediante patrocínio. O mesmo ocorre com o causídico que veicula qualquer forma de publicidade em estádios de futebol ${ }^{23}$, estendendo-se, por lógica, a proibição a qualquer local que receba evento esportivo.

O tópico gera dúvidas, pois acredita-se que a proibição da inserção do nome do advogado em uniformes de times implica, por consequência, a vedação do patrocínio a equipes ou esportistas profissionais brasileiros. Esta última prática, no entanto, é permitida. Não é o patrocínio que fere o regramento ético, mas o fato de o uniforme utilizado nas competições fazer referência ao nome do advogado ou ao escritório ${ }^{24}$.

${ }^{21}$ BANCO DATA. Crefisa. Disponível em: <https://bancodata.com.br/relatorio/crefisa-sacfi $>$. Acesso em: 6 abr. 2018.

${ }^{22}$ SÃO PAULO. Primeira Turma de Ética Profissional do Tribunal de Ética e Disciplina da OAB. Proc. E-4.621/2016. Relator Dr. Eduardo Perez Salusse. São Paulo, 26 de abril de 2016.00 Disponível em: <https://www2.oabsp.org.br/asp/tribunal_etica/pop_ementas.asp?tipoEmenta=1\&ano=201 6\&id_sessao=3\&sequencial=5>. Acesso em: 6 abr. 2018.

${ }^{23}$ SÃO PAULO. Primeira Turma de Ética Profissional do Tribunal de Ética e Disciplina da OAB. Proc. E-2.356/01. Relator Dr. Clodoaldo Ribeiro Machado. São Paulo, 17 de maio de 2001. Disponível em: <https://www2.oabsp.org.br/asp/tribunal_etica/pop_ementas.asp?tipoEmenta=1\&ano=200 1\&id_sessao=4\&sequencial=13>. Acesso em: 6 abr. 2018.

${ }^{24}$ SÃO PAULO. Primeira Turma de Ética Profissional do Tribunal de Ética e Disciplina da OAB. Proc. E-3.028/04. Relator Dr. Luiz Antônio Gambelli. São Paulo, 21 de outubro de 
Por outro lado, o advogado que participar de eventos esportivos, como torneios e maratonas, e fizer uso de camisetas, poderá estampar nelas o logotipo do escritório ou o seu nome, desde que não sejam inseridas informações relativas a telefone e endereço, pois estas descaracterizariam o objetivo da estampa na peça de roupa - que é a identificação do time de cada escritório participante -, e passariam a configurar captação de clientela ${ }^{25}$.

Ademais, também é vedada a inscrição do nome do causídico em instalações sócio-esportivas, por mais que esse tipo de publicidade possa ter objetivos sociais e humanitários, pois tal prática, em decorrência de sua própria natureza, significa captação de causas e clientes ${ }^{26}$.

Além de o advogado poder patrocinar equipes e atletas - apesar de não ser lícito que seu nome esteja presente nos respectivos fardamentos -, ele também pode promover atividades esportivas, "desde que o faça em local fechado, para pessoas determinadas e definidas e de modo não habitual"27, bem como patrocinar eventos ou publicações de caráter científico ou cultural (inovação prevista no art. 45 do CED), tais quais os eventos promovidos pelas Comissões Especiais da OAB.

A diferença entre o patrocínio de equipes e atletas, e o patrocínio de eventos, é que, nesta última hipótese, o nome do advogado ou da sociedade poderá figurar em folders, banners e faixas alusivos à cerimônia,

2004.

Disponível

em:

<https://www2.oabsp.org.br/asp/tribunal_etica/pop_ementas.asp?tipoEmenta=1\&ano=200 4\&id_sessao=9\&sequencial=19>. Acesso em: 15 abr. 2018.

${ }^{25}$ SÃO PAULO. Primeira Turma de Ética Profissional do Tribunal de Ética e Disciplina da OAB. Proc. E-4.295/2013. Relator Dr. João Luiz Lopes. São Paulo, 12 de dezembro de 2013.

Disponível

em: <https://www2.oabsp.org.br/asp/tribunal_etica/pop_ementasano.asp?ano=2013>. Acesso em: 15 abr. 2018.

${ }^{26}$ SÃO PAULO. Primeira Turma de Ética Profissional do Tribunal de Ética e Disciplina da OAB. Proc. E-1.738/98. Relator Dr. Luiz Carlos Branco. São Paulo, 17 de setembro de 1998.

Disponível

em: <https://www2.oabsp.org.br/asp/tribunal_etica/pop_ementas.asp?tipoEmenta=1\&ano=199 8\&id_sessao $=8 \&$ sequencial $=16>$. Acesso em: 6 abr. 2018.

${ }^{27}$ SÃO PAULO. Primeira Turma de Ética Profissional do Tribunal de Ética e Disciplina da OAB. Proc. E-3.027/2004. Relator Dr. Carlos Roberto Fornes Mateucci. São Paulo, 16 de setembro de 2004. Disponível em: <https://www2.oabsp.org.br/asp/tribunal_etica/pop_ementas.asp?tipoEmenta=1\&ano=200 4\&id_sessao=8\&sequencial=13>. Acesso em: 18 jul. 2018. 
respeitando, sempre, as regras gerais da publicidade, como ensina Medina $^{28}$.

Como último item, menciona-se um dos meios mais tradicionais de publicidade, que são os cartões de visita. Nos cartões, o advogado deverá, obrigatoriamente, mencionar seu nome, nome social ou o nome da sociedade, além do número ou dos números de inscrição na $\mathrm{OAB}$, conforme art. 44 do CED.

Por outro lado, como itens facultativos, poderão ser referidos apenas os títulos acadêmicos do advogado e as distinções honoríficas relacionadas à vida profissional, bem como as instituições jurídicas de que faça parte, e as especialidades a que se dedicar, o endereço, e-mail, site, página eletrônica, $Q R$ code, logotipo e a fotografia do escritório, o horário de atendimento e os idiomas em que o cliente poderá ser atendido (art. 44, $\left.\S 1^{\circ}\right)$.

Por fim, o $\S 2^{\circ}$ do art. 44 dispõe sobre as informações proibidas, quais sejam: a inclusão de fotografias pessoais ou de terceiros, bem como menção a qualquer emprego, cargo ou função ocupado, atual ou pretérito, em qualquer órgão ou instituição, salvo o de professor universitário.

\section{CONSIDERAÇÕES FINAIS}

Pelo exposto, resta demonstrado que existem diversas formas de o advogado realizar publicidade de forma correta, respeitando os preceitos éticos e, com isso, valorizando a sua imagem profissional, tornando seu nome conhecido e contribuindo para o prestígio de toda a classe e da advocacia, que devem ser alguns dos objetivos visados pelo advogado quando da promoção da publicidade.

Contudo, engana-se quem pensa que, com a publicidade, irá conquistar novos clientes e impulsionar sua carreira, pois, em vez de valorizar sua imagem profissional, este advogado poderá estar produzindo justamente o efeito contrário, já que a publicidade na advocacia tem um caráter meramente informativo, ou seja, não objetiva a captação de clientes.

Um possível cliente não irá contratar um advogado pelo que ele faz (se é especialista em diversas áreas, por exemplo) ou em razão da

${ }^{28}$ MEDINA, Paulo Roberto de Gouvêa. Comentários ao Código de Ética e Disciplina na Oab. 1. ed. Rio de Janeiro: Forense, 2016, p. 125. 
inovadora publicidade que este realiza; ele irá contratar um advogado pelos motivos que o levam a prestar aqueles serviços.

Se o advogado demonstra publicamente que age com intuito de mercantilização da profissão ou captação de clientela, visando tão somente o seu ganho financeiro, ele está, antes mesmo de cometer uma infração ética - por macular os preceitos éticos vigentes -, manchando sua imagem perante a sociedade.

Uma pessoa que precisa de um advogado não irá contratar um profissional que tem em mente apenas o lucro, se à sua disposição estiverem opções mais dignas.

Para ser constituído, o advogado deverá proceder de modo com que seu ofício seja merecedor de apreço. Somente ao atuar desta forma ele poderá ser chamado para prestar os seus serviços. No caso, se contratado, o motivo não terá sido a utilização de artifícios publicitários típicos de atividade mercantil, por exemplo, mas, sim, o seu merecimento.

Ademais, ainda que grande parte da população não tenha conhecimento das regras a que o advogado deve se submeter, é claro que atitudes que mercantilizam a advocacia não são bem vistas socialmente. Diferentemente de tantas outras profissões, a advocacia não se confunde com um balcão de comércio.

Portanto, é imprescindível que as regras impostas pelo novo Código de Ética e Disciplina da OAB sejam respeitadas pelo advogado, e que ele entenda qual a verdadeira essência da publicidade, pois, somente assim, sua figura será respeitada e ele poderá ser escolhido para exercer seu nobre ofício em função dos que necessitam.

Quando bem executada, é verdade que a publicidade torna o nome do profissional conhecido e valoriza sua imagem, como nos casos em que o advogado esclarece assunto jurídico de interesse geral em suas participações na mídia.

Todavia, o verdadeiro marketing do advogado é a sua atuação destemida, independente, honesta, pautada no decoro, veracidade, lealdade, dignidade e boa-fé. O prestígio profissional do advogado decorre de sua competência, talento, honradez e nobreza no exercício profissional, e não por causa da publicidade que realiza.

O propósito basilar da publicidade na advocacia não é a venda de um produto, mas tornar públicas informações objetivas acerca do advogado que dela se utiliza, noticiando, sem alardes, de forma discreta e sóbria, a sua disponibilidade para atuar na defesa de quem, porventura, necessitar de seus serviços. 


\section{REFERÊNCIAS BIBLIOGRÁFICAS}

BANCO DATA. Crefisa. Disponível em: <https://bancodata.com.br/relatorio/crefisa-sa-cfi >. Acesso em: 6 abr. 2018.

BARONI, Robison. Cartilha de Ética Profissional do Advogado. 4. ed. São Paulo: LTR, 2001.

COÊLHO, Marcus Vinícius Furtado. Comentários ao novo código de ética dos advogados. 2. ed. São Paulo: Saraiva, 2017.

GANDRA, Alana. Pesquisa diz que, de 69 milhões de casas, só 2,8\% não têm TV no Brasil. Rio de Janeiro, 21 de fevereiro de 2018. Disponível em:

$<$ http://agenciabrasil.ebc.com.br/economia/noticia/2018-02/uso-de-celular-e-acesso-internet-saotendencias-crescentes-no-brasil>. Acesso em: 12 jul. 2018.

GARCIA, Ismar Estulano; PIMENTA, Ismara Estulano. Comentários ao novo Código de Ética e Disciplina da OAB. Goiânia: AB, 2016.

KANTAR IBOPE MEDIA. Mais de 84 mil marcas foram expostas na mídia em 2017. Disponível em: <https://www.kantaribopemedia.com/mais-de-84-mil-marcas-foram-expostas-na-midia-em2017>. Acesso em: 15 fev. 2018

MAMEDE, Gladston. A Advocacia e a Ordem dos Advogados do Brasil. 1. ed. Porto Alegre: Síntese, 1999.

MEDINA, Paulo Roberto de Gouvêa. Comentários ao Código de Ética e Disciplina na Oab. 1. ed. Rio de Janeiro: Forense, 2016.

PORTINARI, Natália; HERNANDES, Raphael. Fake news ganha espaço no Facebook e jornalismo profissional perde. São Paulo, fevereiro de 2018. Disponível em:

<https://www 1.folha.uol.com.br/poder/2018/02/fake-news-ganha-espaco-no-facebook-e-jornalismoprofissional-perde.shtml>. Acesso em: 24 jul. 2018.

SÃO PAULO. Primeira Turma de Ética Profissional do Tribunal de Ética e Disciplina da OAB. Proc. E-2.340/01. Relator Dr. João Teixeira Grande. São Paulo, 17 de maio de 2001. Disponível em: $<$ https://www2.oabsp.org.br/asp/tribunal_etica/pop_ementas.asp?tipoEmenta=1\&ano=2001\&id_sessa $\mathrm{o}=4 \&$ sequencial $=5>$. Acesso em: 15 abr. 2018

Primeira Turma de Ética Profissional do Tribunal de Ética e Disciplina da OAB. Proc. E4.459/2014. Relator Dra. Renata Mangueira de Souza. São Paulo, 16 de abril de 2015. Disponível em:

$<$ https://www2.oabsp.org.br/asp/tribunal_etica/pop_ementas.asp?tipoEmenta=1\&ano=2015\&id_sessa $\mathrm{o}=3 \&$ sequencial $=1>$. Acesso em: 15 fev. 2018.

Primeira Turma de Ética Profissional do Tribunal de Ética e Disciplina da OAB. Proc. 1.684/98. Relator Dr. João Teixeira Grande. São Paulo, 21 de maio de 1998. Disponível em: <https://www2.oabsp.org.br/asp/tribunal_etica/pop_ementas.asp?tipoEmenta=1\&ano=1998\&id_sessa $\mathrm{o}=4 \&$ sequencial $=8>$. Acesso em: 15 fev. 2018 
Primeira Turma de Ética Profissional do Tribunal de Ética e Disciplina da OAB. Proc. E4.857/2017. Relator Dr. Luiz Antonio Gambelli. São Paulo, 17 de agosto de 2017. Disponível em: $<$ https://www2.oabsp.org.br/asp/tribunal_etica/pop_ementas.asp?tipoEmenta=1\&ano=2017\&id_sessa o=7\&sequencial=30>. Acesso em: 15 fev. 2018.

. Primeira Turma de Ética Profissional do Tribunal de Ética e Disciplina da OAB. Proc. E2.748/03. Relator Dr. Osmar de Paula Conceição Júnior. São Paulo, 11 de dezembro de 2003. Disponível em:

$<$ https://www2.oabsp.org.br/asp/tribunal_etica/pop_ementas.asp?tipoEmenta=1\&ano=2003\&id_sessa $\mathrm{o}=11 \&$ sequencial=1>. Acesso em: 15 fev. 2018.

Primeira Turma de Ética Profissional do Tribunal de Ética e Disciplina da OAB. Proc. E3.186/05. Relator Dr. Guilherme Florindo Figueiredo. São Paulo, 16 de junho de 2005. Disponível em: 〈http://www.oabsp.org.br/tribunal-de-etica-e-disciplina/melhores-pareceres/E318605>. Acesso em: 24 jul. 2018

Primeira Turma de Ética Profissional do Tribunal de Ética e Disciplina da OAB. Proc. E4.247/2013. Relator Dr. Sylas Kok Ribeiro. São Paulo, 16 de maio de 2013. Disponível em: $<$ https://www2.oabsp.org.br/asp/tribunal_etica/pop_ementas.asp?tipoEmenta=1\&ano=2013\&id_sessa $\mathrm{o}=3 \&$ sequencial $=8>$. Acesso em: 24 jul. 2018.

. Primeira Turma de Ética Profissional do Tribunal de Ética e Disciplina da OAB. Proc. E2.356/01. Relator Dr. Clodoaldo Ribeiro Machado. São Paulo, 17 de maio de 2001. Disponível em: $<$ https://www2.oabsp.org.br/asp/tribunal_etica/pop_ementas.asp?tipoEmenta=1\&ano=2001\&id_sessa $\mathrm{o}=4 \&$ sequencial $=13>$. Acesso em: 6 abr. 2018.

. Primeira Turma de Ética Profissional do Tribunal de Ética e Disciplina da OAB. Proc. E4.621/2016. Relator Dr. Eduardo Perez Salusse. São Paulo, 26 de abril de 2016. 0. Disponível em: $<$ https://www2.oabsp.org.br/asp/tribunal_etica/pop_ementas.asp?tipoEmenta=1\&ano=2016\&id_sessa $\mathrm{o}=3 \&$ sequencial $=5>$. Acesso em: 6 abr. 2018.

. Primeira Turma de Ética Profissional do Tribunal de Ética e Disciplina da OAB. Proc. E4.051/2011. Relator Dra. Célia Maria Nicolau Rodrigues. São Paulo, 20 de outubro de 2011. Disponível em: $<$ https://www2.oabsp.org.br/asp/tribunal_etica/pop_ementas.asp?tipoEmenta $=1 \&$ ano=2011\&id_sessa $\mathrm{o}=9 \&$ sequencial $=2>$. Acesso em: 17 jul. 2018.

Primeira Turma de Ética Profissional do Tribunal de Ética e Disciplina da OAB. Proc. E4.176/2012. Relator Dr. Flávio Pereira Lima. São Paulo, 18 de outubro de 2012. Disponível em: $<$ https://www2.oabsp.org.br/asp/tribunal_etica/pop_ementas.asp?tipoEmenta $=1 \&$ ano=2012\&id_sessa $\mathrm{o}=8 \&$ sequencial $=9>$. Acesso em: 24 jul. 2018.

. Primeira Turma de Ética Profissional do Tribunal de Ética e Disciplina da OAB. Proc. E3.028/04. Relator Dr. Luiz Antônio Gambelli. São Paulo, 21 de outubro de 2004. Disponível em: $<$ https://www2.oabsp.org.br/asp/tribunal_etica/pop_ementas.asp?tipoEmenta=1\&ano=2004\&id_sessa o=9\&sequencial=19>. Acesso em: 15 abr. 2018.

. Primeira Turma de Ética Profissional do Tribunal de Ética e Disciplina da OAB. Proc. E4.295/2013. Relator Dr. João Luiz Lopes. São Paulo, 12 de dezembro de 2013. Disponível em: <https://www2.oabsp.org.br/asp/tribunal_etica/pop_ementasano.asp?ano=2013>. Acesso em: 15 abr. 2018. 
Primeira Turma de Ética Profissional do Tribunal de Ética e Disciplina da OAB. Proc. E1.738/98. Relator Dr. Luiz Carlos Branco. São Paulo, 17 de setembro de 1998. Disponível em: $<$ https://www2.oabsp.org.br/asp/tribunal_etica/pop_ementas.asp?tipoEmenta=1\&ano=1998\&id_sessa $\mathrm{o}=8 \&$ sequencial $=16>$. Acesso em: 6 abr. 2018.

. Primeira Turma de Ética Profissional do Tribunal de Ética e Disciplina da OAB. Proc. E3.027/2004. Relator Dr. Carlos Roberto Fornes Mateucci. São Paulo, 16 de setembro de 2004.

Disponível em:

$<$ https://www2.oabsp.org.br/asp/tribunal_etica/pop_ementas.asp?tipoEmenta=1\&ano=2004\&id_sessa $\mathrm{o}=8 \&$ sequencial $=13>$. Acesso em: 18 jul. 2018.

SILVA, José Afonso da. Comentário contextual à Constituição. 3. ed. Malheiros, 2007.

VON MISES, Ludwig. Ação humana. Tradução por Donald Stewart Jr. São Paulo: Instituto Ludwig von Mises Brasil, 2010. 